\title{
Emotional predictors and behavioral triggers of acute coronary syndrome
}

\author{
Karina W. Davidson, PhD \\ Departments of Medicine and Psychiatry, Columbia University College of Physicians and Surgeons, \\ Cardiovascular Institute, Mount Sinai School of Medicine, New York, NY
}

\begin{abstract}
Mounting evidence suggests that depression, anxiety, and hostility/anger may each be an independent risk factor for acute coronary syndrome (ACS) occurrence. Data specific to the role of these negative emotional states in predisposing to imminent ACS risk are limited, however. Additionally, a number of studies have indicated that certain situational triggers (such as intense physical exertion) and behavioral triggers (such as acute anxiety or anger) are predictive of imminent occurrence of an ACS. Despite these findings, the use of emotional or behavioral information to identify persons at high risk for imminent ACS onset is not yet practical. Further research is needed to facilitate such patient identification.
\end{abstract}

Numerous systematic reviews indicate that psychosocial factors are predictive of an initial acute coronary syndrome (ACS), ${ }^{1-8}$ defined as myocardial infarction (MI), unstable angina, or sudden cardiac death. Psychosocial factors under active investigation for their role in ACS onset include chronic negative emotional states (eg, depression, hostility, anxiety) as well as situational and behavioral triggers (eg, acute anger, unusual intense physical activity). This review will present evidence for each grouping of risk markers and then discuss the studies required to better identify and treat patients who have these psychosocial vulnerabilities.

\section{Negative Emotional States}

Increasing epidemiologic and pathophysiologic evidence suggests that depression, anxiety, and hostility/anger may each be an independent risk factor for initial occurrence of a cardiovascular event. 4,8 The vast majority of evidence has been accumulated for depression, and many meta-analyses and systematic reviews now indicate that depression—as either a clinical diagnosis or an elevation in self-reported symptoms-is a strong, consistent, independent predictor of ACS incidence. ${ }^{9-11}$

For example, in one meta-analysis of studies examining depression and the incidence of coronary heart disease (CHD) events, the presence of depressive symptoms conferred a relative risk of 1.49 for CHD events (95\% confidence interval [CI], 1.16 to 1.92), and the presence of clinical depression conferred a relative risk of 2.69 (95\% CI, 1.63 to 4.43 ), which suggests a dose-response-like association between depression and ACS onset. ${ }^{9}$ Figure 1 shows the incident risk of CHD events associated with depression (depressed mood and clinical depression) from this meta-analysis relative to the risk associated with established risk factors for CHD. ${ }^{4}$

Correspondence: Karina W. Davidson, PhD, Department of Medicine, Columbia University College of Physicians and Surgeons, 622 W. 168th Street, PH9 Center, Room 948, New York, NY 10032; kd2124@ columbia.edu.

Dr. Davidson reported that she has no financial relationships that pose a potential conflict of interest with this article. 


\section{Major depression}

Major depressive disorder is most appropriately diagnosed through direct patient interview, preferably by trained professionals who look for evidence of severely depressed mood lasting at least 2 consecutive weeks, other concomitant symptoms (such as change in eating or sleeping habits), and evidence of associated functional impairment. Because this interview approach is not convenient for large epidemiologic studies, evaluation of major depression by interview in longitudinal epidemiologic studies has been sparse, ${ }^{12,13}$ and only a limited number of other studies have also evaluated the role of a history of depressive disorders ${ }^{14}$ or a history of depression treatment. ${ }^{14-18}$

\section{Depressive symptoms}

The impact of self-reported depressive symptoms on cardiac outcomes has been studied more widely - in community settings, among the elderly, and in various cardiac settings-using scales such as the Beck Depression Inventory and the Center for Epidemiological Studies Depression Scale. Notably, these scales assess only the presence of recent depressive symptoms. Nevertheless, despite this important limitation, one-time assessment of healthy participants using these scales has generally revealed a significant relationship between depressive symptoms and future adverse cardiac events. ${ }^{9,18}$ As further evidence of a gradient relationship, the frequency of cardiac events increases as the level of depressive symptoms increases. ${ }^{13,19}$

Depression is a complex phenotype, and some have argued that subtypes, or intermediary phenotypes, of depression may be particularly predictive of ACS incidence and recurrence. 20 Interestingly, the first article ever published documenting a link between depression and coronary artery disease focused exclusively on melancholic depression, or endogenous depression. $^{21}$

\section{Anxiety}

Anxiety is defined as a future-oriented negative emotion resulting from perceived threat and accompanied by perceived lack of control and lack of predictability. ${ }^{22}$ Like depression, anxiety occurs along a continuum, but it is characterized as pathological when it becomes chronic, has intensity out of proportion to any real threat, and leaves the affected person with seriously impaired ability to function.

There are many recognized anxiety disorders, including generalized anxiety disorder, panic attacks, obsessive-compulsive disorder, posttraumatic stress syndrome, and various forms of phobia. As a group, these anxiety disorders constitute one of the most common forms of psychiatric illness. Moreover, anxiety disorders and major depression are highly comorbid. 23 Although some interesting epidemiologic studies have indicated that anxiety may predict new ACS events, ${ }^{24-26}$ there are a few that have yielded mixed results. ${ }^{27,28}$

\section{Hostility and anger}

Angry and hostile feelings are overlapping emotions and, when experienced frequently, indicate broader, more enduring temperaments or personality styles. Hostility is a cynical, suspicious, and resentful attitude toward others; negative social exchanges, such as sarcasm or impatience, typify individuals with hostility. In contrast, individuals with anger difficulties can have warm, appropriate interpersonal skills and may display verbal aggression or other outbursts only when provoked. Unlike depressive and anxiety disorders, professionally diagnosed, syndromal anger and hostility are not yet recognized by psychiatric nosology.

Relatively few longitudinal studies have been conducted using measures of hostility in healthy cohorts. These studies have reported both the presence 29,30 and the absence ${ }^{31}$ of positive 
associations. In a recent systematic review, 7 of 11 studies showed hostility to be a significant risk factor for $\mathrm{CHD}^{8} \mathrm{~A}$ case-control study involving participants in the Multiple Risk Factor Intervention Trial (MRFIT) employed a structured interview (as opposed to a questionnaire) designed to elicit information regarding signs of hostility, including irritation, arrogance, uncooperativeness, and angry feelings. ${ }^{30}$ It revealed that men with high hostility levels were more likely to die of cardiovascular disease than men with low hostility levels (adjusted odds ratio $=1.61 ; 95 \%$ CI, 1.09 to 2.39 ) in this initially healthy but high-risk cohort. ${ }^{30}$ The investigators chose the structured interview to overcome participants' potential to underreport or underrecognize hostile tendencies when completing a questionnaire. ${ }^{30}$

Over time, specific measurements of chronic anger, ${ }^{32-37}$ including both unhealthy anger expression $^{34}$ and suppression, ${ }^{37}$ have accumulated, permitting examination of their relationship to adverse cardiac outcomes in longitudinal follow-up of disease-free cohorts. A number of these studies have shown a positive association. ${ }^{32,33,35-37}$ Moreover, a recent report from the Framingham study demonstrated an association between anger/hostility and the development of atrial fibrillation and total-cause mortality over a 10 -year period, ${ }^{38}$ and another study has observed a relationship between anger expression and development of stroke. 39 Combined, these observations suggest that anger is worthy of further study as a factor in the development of CHD. As with hostility, however, various subscales have been used to study anger, which makes standardization across studies difficult.

\section{Data specific to imminent ACS risk are few}

The majority of the negative emotional states have not been tested for their ability to predict an ACS in the near future. Further, negative emotional and cognitive states that may be implicated in the development of CHD or other cardiovascular disease may be quantitatively or even qualitatively different from those psychosocial factors that identify a patient at imminent risk for an ACS.

\section{Situational and Behavioral Triggers}

Evidence for imminent risk or trigger status can be obtained from retrospective reports, from witness accounts (if available), or prospectively from electronic diaries coupled with ambulatory electrocardiogram recordings or an implantable cardioverter-defibrillator (ICD). Triggers of an ACS include external stimuli (eg, cocaine use, air pollution, ambient temperature), patient activities (eg, eating a meal high in saturated fat, unusual physical exertion), and emotional reactions such as extreme anger or anxiety. 1,2,7,40,41 Myocardial stunning has also been reported immediately after acute emotional stress but has generally been reversible in these cases. ${ }^{42,43}$ In an observational study, Burg et al found that ICD shocks preceded by an anger episode (as recorded by diary) were more frequent in patients with high trait levels of anger (according to the Speilberger Trait Personality Inventory) and that shocks preceded by an anxiety episode were more frequent in patients with high trait levels of anxiety. 44 A systematic review by Strike and Steptoe showed that physical exertion (particularly in poorly conditioned individuals), emotional stress, anger, and extreme excitement are all probable triggers for an ACS. ${ }^{7}$ A recent meta-analysis suggests that emotional stress immediately precedes MI in approximately $7 \%$ of MI cases and is a more frequent ACS trigger for women than for men. ${ }^{1}$

Table 1 presents examples of triggers that have been found to predict an imminent ACS. Some of these triggers may represent episodes or situations that can lead to an imminent ACS in any apparently healthy person, whereas some may operate only in apparently healthy persons who have chronic negative emotional states or other psychosocial vulnerabilities. 


\section{The Psychosocially Vulnerable Patient}

This selective overview suggests that patients' emotional states are frequently implicated in the onset of an ACS but that the use of behavioral or emotional information to identify those at high risk for imminent ACS onset is not yet practical. Triggers are, by definition, state-like, but their impact may be amplified by trait-like characteristics, such as high dispositional anger, anxiety, hostility, or chronic environmental stress.

The previously mentioned analysis of the MRFIT study by Matthews et $\mathrm{al}^{30}$ suggests that patients identified as "high risk" by conventional risk factors, and who additionally possess high trait hostility, should be monitored closely, as they are at risk for cardiovascular death. Additionally, the Burg study of patients with ICDs suggests that arrhythmia may be induced by acute anxiety or anger in those prone to have such emotions chronically. ${ }^{44}$

Such studies have two research implications. First, controlled laboratory studies that induce acute negative emotion in those with chronic negative emotional states may help reveal the pathophysiologic processes implicated in immediate ACS onset. Interventions for these psychosocially vulnerable patients await such studies. Second, we must begin to consider that in addition to the psychosocially vulnerable patient, we may have psychosocially vulnerable situations, about which we know little at this time.

\section{Acknowledgements}

The author thanks Lucia Dettenborn, $\mathrm{PhD}$, for her assistance with the presentation on which this manuscript, in part, is based.

This work was supported by grants HC-25197, HL-76857, HL-80665, and HL-84034 from the National Heart, Lung, and Blood Institute. The project described was supported by grant number UL1 RR024156 from the National Center for Research Resources (NCRR), a component of the National Institutes of Health (NIH) and the NIH Roadmap for Medical Research, and its contents are solely the responsibility of the author and do not necessarily represent the official view of NCRR or NIH. Information on NCRR is available at http://www.ncrr.nih.gov/. Information on Reengineering the Clinical Research Enterprise can be obtained from http://nihroadmap.nih.gov/clinicalresearch/overview-translational.asp.

\section{References}

1. Culić V, Eterović D, Mirić D. Meta-analysis of possible external triggers of acute myocardial infarction. Int J Cardiol 2005;99:1-8. [PubMed: 15721492]

2. Kloner RA. Natural and unnatural triggers of myocardial infarction. Prog Cardiovasc Dis 2006;48:285300. [PubMed: 16517249]

3. Nicholson A, Kuper H, Hemingway H. Depression as an aetiologic and prognostic factor in coronary heart disease: a meta-analysis of 6362 events among 146538 participants in 54 observational studies. Eur Heart J 2006;27:2763-2774. [PubMed: 17082208]

4. Rozanski A, Blumenthal JA, Davidson KW, Saab PG, Kubzansky L. The epidemiology, pathophysiology, and management of psychosocial risk factors in cardiac practice: the emerging field of behavioral cardiology. J Am Coll Cardiol 2005;45:637-651. [PubMed: 15734605]

5. Rosengren A, Hawken S, Ounpuu S, et al. Association of psychosocial risk factors with risk of acute myocardial infarction in 11119 cases and 13648 controls from 52 countries (the INTER-HEART study): case-control study. Lancet 2004;364:953-962. [PubMed: 15364186]

6. Servoss SJ, Januzzi JL, Muller JE. Triggers of acute coronary syndromes. Prog Cardiovasc Dis 2002;44:369-380. [PubMed: 12024335]

7. Strike PC, Steptoe A. Behavioral and emotional triggers of acute coronary syndromes: a systematic review and critique. Psychosom Med 2005;67:179-186. [PubMed: 15784781]

8. Suls J, Bunde J. Anger, anxiety, and depression as risk factors for cardiovascular disease: the problems and implications of overlapping affective dispositions. Psychol Bull 2005;131:260-300. [PubMed: 15740422] 
9. Rugulies R. Depression as a predictor for coronary heart disease: a review and meta-analysis. Am J Prev Med 2002;23:51-61. [PubMed: 12093424]

10. Wulsin LR, Singal BM. Do depressive symptoms increase the risk for the onset of coronary disease? A systematic quantitative review. Psychosom Med 2003;65:201-210. [PubMed: 12651987]

11. Van der Kooy K, van Hout H, Marwijk H, Marten H, Stehouwer C, Beekman A. Depression and the risk for cardiovascular diseases: systematic review and meta analysis. Int J Geriatr Psychiatry 2007;22:613-626. [PubMed: 17236251]

12. Ford DE, Mead LA, Chang PP, Cooper-Patrick L, Wang NY, Klag MJ. Depression is a risk factor for coronary artery disease in men: the Precursors Study. Arch Intern Med 1998;158:1422-1426. [PubMed: 9665350]

13. Penninx BW, Beekman AT, Honig A, et al. Depression and cardiac mortality: results from a community-based longitudinal study. Arch Gen Psychiatry 2001;58:221-227. [PubMed: 11231827]

14. Pratt LA, Ford DE, Crum RM, Armenian HK, Gallo JJ, Eaton WW. Depression, psychotropic medication, and risk of myocardial infarction. Prospective data from the Baltimore ECA follow-up. Circulation 1996;94:3123-3129. [PubMed: 8989119]

15. Cohen HW, Madhavan S, Alderman MH. History of treatment for depression: risk factor for myocardial infarction in hypertensive patients. Psychosom Med 2001;63:203-209. [PubMed: 11292266]

16. Rutledge T, Reis SE, Olson MB, et al. Depression symptom severity and reported treatment history in the prediction of cardiac risk in women with suspected myocardial ischemia: the NHLBI-sponsored WISE study. Arch Gen Psychiatry 2006;63:874-880. [PubMed: 16894063]

17. Sauer WH, Berlin JA, Kimmel SE. Effect of antidepressants and their relative affinity for the serotonin transporter on the risk of myocardial infarction. Circulation 2003;108:32-36. [PubMed: 12821544]

18. Wassertheil-Smoller S, Shumaker S, Ockene J, et al. Depression and cardiovascular sequelae in postmenopausal women: the Women's Health Initiative (WHI). Arch Intern Med 2004;164:289-298. [PubMed: 14769624]

19. Rowan PJ, Haas D, Campbell JA, Maclean DR, Davidson KW. Depressive symptoms have an independent, gradient risk for coronary heart disease incidence in a random, population-based sample. Ann Epidemiol 2005;15:316-320. [PubMed: 15780780]

20. Davidson KW, Rieckmann N, Rapp MA. Definitions and distinctions among depressive syndromes and symptoms: implications for a better understanding of the depression-cardiovascular disease association. Psychosom Med 2005;67(Suppl 1):S6-S9. [PubMed: 15953804]

21. Malzberg B. Mortality among patients with involution melancholia. Am J Psychiatry 1937;93:12311238.

22. Barlow, DH. Anxiety and its Disorders: The Nature and Treatment of Anxiety and Panic. New York, NY: Guilford Press; 1988.

23. Hirschfeld RM. The comorbidity of major depression and anxiety disorders: recognition and management in primary care. Prim Care Companion J Clin Psychiatry 2001;3:244-254. [PubMed: 15014592]

24. Kawachi I, Colditz GA, Ascherio A, et al. Prospective study of phobic anxiety and risk of coronary heart disease in men. Circulation 1994;89:1992-1997. [PubMed: 8181122]

25. Kubzansky LD, Kawachi I, Weiss ST, Sparrow D. Anxiety and coronary heart disease: a synthesis of epidemiological, psychological, and experimental evidence. Ann Behav Med 1998;20:47-58. [PubMed: 9989308]

26. Kubzansky LD, Kawachi I, Spiro A III, et al. Is worrying bad for your heart? A prospective study of worry and coronary heart disease in the Normative Aging Study. Circulation 1997;95:818-824. [PubMed: 9054737]

27. Todaro JF, Shen BJ, Niaura R, Spiro A III, Ward KD. Effect of negative emotions on frequency of coronary heart disease (The Normative Aging Study). Am J Cardiol 2003;92:901-906. [PubMed: 14556863]

28. McCarron P, Gunnell D, Harrison GL, Okasha M, Davey Smith G. Temperament in young adulthood and later mortality: prospective observational study. J Epidemiol Community Health 2003;57:888892. [PubMed: 14600116] 
29. Niaura R, Banks SM, Ward KD, et al. Hostility and the metabolic syndrome in older males: the Normative Aging Study. Psychosom Med 2000;62:7-16. [PubMed: 10705906]

30. Matthews KA, Gump BB, Harris KF, Haney TL, Barefoot JC. Hostile behaviors predict cardiovascular mortality among men enrolled in the Multiple Risk Factor Intervention Trial. Circulation 2004;109:66-70. [PubMed: 14662707]

31. Sykes DH, Arveiler D, Salters CP, et al. Psychosocial risk factors for heart disease in France and Northern Ireland: the Prospective Epidemiological Study of Myocardial Infarction (PRIME). Int J Epidemiol 2002;31:1227-1234. [PubMed: 12540727]

32. Haynes SG, Feinleib M, Kannel WB. The relationship of psychosocial factors to coronary heart disease in the Framingham Study. III. Eight-year incidence of coronary heart disease. Am J Epidemiol 1980;111:37-58. [PubMed: 7352459]

33. Chang PP, Ford DE, Meoni LA, Wang NY, Klag MJ. Anger in young men and subsequent premature cardiovascular disease: the Precursors Study. Arch Intern Med 2002;162:901-906. [PubMed: 11966341]

34. Eng PM, Fitzmaurice G, Kubzansky LD, Rimm EB, Kawachi I. Anger expression and risk of stroke and coronary heart disease among male health professionals. Psychosom Med 2003;65:100-110. [PubMed: 12554821]

35. Williams JE, Paton CC, Siegler IC, Eigenbrodt ML, Nieto FJ, Tyroler HA. Anger proneness predicts coronary heart disease risk: prospective analysis from the Atherosclerosis Risk in Communities (ARIC) study. Circulation 2000;101:2034-2039. [PubMed: 10790343]

36. Kawachi I, Sparrow D, Spiro A III, Vokonas P, Weiss ST. A prospective study of anger and coronary heart disease. The Normative Aging Study. Circulation 1996;94:2090-2095. [PubMed: 8901656]

37. Gallacher JE, Yarnell JW, Sweetnam PM, Elwood PC, Stansfeld SA. Anger and incident heart disease in the Caerphilly study. Psychosom Med 1999;61:446-453. [PubMed: 10443752]

38. Eaker ED, Sullivan LM, Kelly-Hayes M, D'Agostino RB Sr, Benjamin EJ. Anger and hostility predict the development of atrial fibrillation in men in the Framingham Offspring Study. Circulation 2004;109:1267-1271. [PubMed: 14993133]

39. Everson SA, Kaplan GA, Goldberg DE, Lakka TA, Sivenius J, Salonen JT. Anger expression and incident stroke: prospective evidence from the Kuopio ischemic heart disease study. Stroke 1999;30:523-528. [PubMed: 10066846]

40. Mittleman MA, Maclure M, Nachnani M, Sherwood JB, Muller JE. Educational attainment, anger, and the risk of triggering myocardial infarction onset. The Determinants of Myocardial Infarction Onset Study Investigators. Arch Intern Med 1997;157:769-775. [PubMed: 9125009]

41. Mittleman MA, Maclure M, Sherwood JB, et al. Triggering of acute myocardial infarction onset by episodes of anger. Determinants of Myocardial Infarction Onset Study Investigators. Circulation 1995;92:1720-1725. [PubMed: 7671353]

42. Wittstein IS, Thiemann DR, Lima JA, et al. Neurohumoral features of myocardial stunning due to sudden emotional stress. N Engl J Med 2005;352:539-548. [PubMed: 15703419]

43. Wittstein IS. The broken heart syndrome. Cleve Clin J Med 2007;74(Suppl 1):S17-S22. [PubMed: 17455537]

44. Burg MM, Lampert R, Joska T, Batsford W, Jain D. Psychological traits and emotion-triggering of ICD shock-terminated arrhythmias. Psychosom Med 2004;66:898-902. [PubMed: 15564355]

45. Wilson PW, D'Agostino RB, Levy D, Belanger AM, Silbershatz H, Kannel WB. Prediction of coronary heart disease using risk factor categories. Circulation 1998;97:1837-1847. [PubMed: 9603539] 


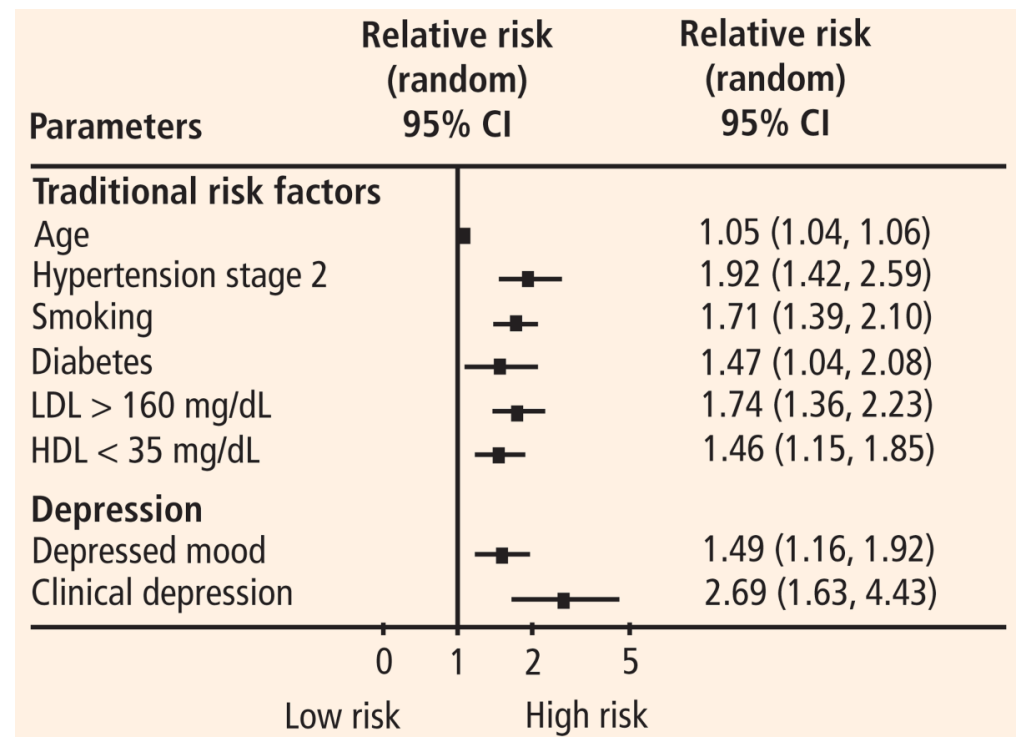

FIGURE 1.

Risk of coronary heart disease (CHD) events associated with traditional Framingham risk factors versus the risk associated with depression. Risk ratios for the traditional risk factors are those reported for men followed up in the Framingham study; ${ }^{45}$ risk ratios for depressed mood and clinical depression are from a meta-analysis by Rugulies et al. ${ }^{9}$ Reprinted from Journal of the American College of Cardiology (Rozanski A, et al. The epidemiology, pathophysiology, and management of psychosocial risk factors in cardiac practice: the emerging field of behavioral cardiology. J Am Coll Cardiol 2005; 45:637-651.), copyright 2005, with permission from the American College of Cardiology. 
TABLE 1

Situational and psychosocial triggers of CHD: Profile of studies assessing their association with imminent $\mathbf{A C S}^{*}$

\begin{tabular}{|c|c|c|c|}
\hline Trigger & No. of studies & Participants & $\begin{array}{c}\text { No. of studies showing } \\
\text { association with imminent } \\
\text { ACS }\end{array}$ \\
\hline Earthquakes & 7 & $\begin{array}{l}\text { Vast majority with elevated risk factors } \\
\text { for CVD or clinical histories }\end{array}$ & 6 \\
\hline Sporting events & 4 & Men & 3 \\
\hline War & 6 & Men & 2 \\
\hline Emotional distress and anger & 5 & Men and women & 5 \\
\hline Emotional stress & 5 & Men and women & 5 \\
\hline
\end{tabular}

$\mathrm{CHD}=$ coronary heart disease ACS = acute coronary syndrome; $\mathrm{CVD}=$ cardiovascular disease 